\title{
PENGEMBANGAN MODUL PEMBELAJARAN PECAHAN SEDERHANA KELAS III SD DENGAN PENDEKATAN CONTEXTUAL TEACHING AND LEARNING (CTL)
}

\author{
Dyah Tri Wahyuningtyas, \\ Ester Pratama \\ Universitas Kanjuruhan Malang \\ Malang, Indonesia \\ E-mail: dyahtriwahyu@unikama.ac.id
}

\begin{abstract}
Abstrak
Penelitian ini secara umum bertujuan untuk menghasilkan suatu modul pembelajaran materi pecahan sederhana yang valid, efektif, dan praktis dengan mengembangkan tujuh unsur pada pendekatan Contextual Teaching and Learning (CTL). Jenis penelitian ini adalah penelitian pengembangan. Model penelitian pengembangan menggunakan model 4-D. Tahap penelitian dilakukan dalam empat tahap, yaitu: (1) Tahap pendefinisian (define); (2) tahap perancangan (design); (3) tahap pengembangan (develop); dan tahap penyebaran (disseminate). Berdasarkan pada tahap pengembangan melalui validasi, diperoleh bahwa modul yang dikembangkan valid dengan ketercapaian validasi modul 96,73\% dan ketercapaian validasi materi 76,46\%. Kepraktisan modul diperoleh dari ketercapaian persentase aktivitas guru selama dua pertemuan mencapai $82 \%$ dan $91,42 \%$. Keefektifan modul diperoleh dari hasil persentase aktivitas siswa selama pertemuan pertama dan kedua mencapai $85,14 \%$ dan $90,85 \%$, persentase respon positif siswa terhadap modul pembelajaran mencapai $95,66 \%$, dan rata-rata hasil belajar yang diperoleh oleh siswa mencapai nilai 88. Berdasarkan hasil penelitian tersebut, maka modul pembelajaran matematika layak digunakan di lapangan.
\end{abstract}

Kata Kunci: Contextual Teaching and Learning, Modul, Pecahan

\begin{abstract}
This research generally had purpose to produce a modest fraction of material learning module are valid, effective, and practical by developing the seven elements of the approach Contextual Teaching and Learning (CTL). The research development model used a 4-D model. The study was conducted in four steps: (1) definition step; (2) design step; (3) development step; and (4) the disseminate step. Based on the development step through validation, it is found that the module developed is valid with $96,73 \%$ validation module achievement and material validation achievement $76,46 \%$. Module practicality is obtained from the percentage of teacher activity during two meetings reached $82 \%$ and $91,42 \%$. The effectiveness of module obtained from the result of the percentage of student activity during the first and second meeting reached $85,14 \%$ and $90,85 \%$, the percentage of student's positive responses to the learning module reached $95,66 \%$, and the average learning outcomes obtained by students reached 88 . Based on the result of the research, it can be concluded that the mathematic learning module is suitable for use in the class.
\end{abstract}

Keywords: Contextual Teaching and Learning, Module, Fractional

\section{PENDAHULUAN}

Matematika digunakan sebagai alat untuk mengembangkan cara berpikir. Untuk itulah matematika sangat diperlukan dalam kehidupan sehari-hari. Salah satu materi pembelajaran matematika yang berkaitan dengan kehidupan sehari-hari adalah materi pecahan sederhana. Materi pecahan bukanlah materi yang mudah karena materi tersebut bersifat abstrak. Keabstrakkan tersebut yang membuat siswa kesulitan untuk memahami materi. Mengenal pecahan sederhana merupakan salah satu materi penting yang harus dikuasai oleh siswa pada tingkat Sekolah Dasar. Namun pada kenyataannya, konsep pecahan bukanlah konsep yang sederhana untuk dipelajari dan dipahami oleh siswa. Makna pecahan yang begitu bervariasi merupakan salah satu penyebab kesulitan siswa dalam pembelajaran pecahan. Di sisi lain, pecahan sangat berguna bagi siswa karena materi ini akan membantu siswa dalam mempelajari materi matematika yang lain pada jenjang berikutnya. Kurangnya pemahaman siswa mengenai pecahan merupakan faktor yang mendasari pada penguasaan matematika yang kurang memadai. Unsur pembelajaran pada materi 
pecahan sederhana diajarkan pada siswa kelas III adalah penjumlahan dan pengurangan pecahan berpenyebut sama. Materi tersebut merupakan materi kelas III pada semester ganjil. Materi ini mengacu pada Kurikulum 2013.

Kondisi perkembangan kognitif siswa kelas III tingkat sekolah dasar berada pada tahap operasional konkret. Sunarto and Hartono (2008) mengemukakan bahwa anak pada usia 7 sampai 11 tahun berada pada tahap operasional konkret. Pada tahap ini, siswa pada usia tersebut dapat melakukan identifikasi (mengenali sesuatu), negasi (mengingkari sesuatu), dan reprokasi (mencari hubungan timbal balik antara beberapa hal). Sehingga pemberian materi pembelajaran matematika yang abstrak dengan memberikan permasalahan yang berkaitan dalam kehidupan sehari-hari dapat mengkonkretkan pembelajaran matematika.

Dalam memberikan materi pembelajaran, guru sebaiknya tidak secara langsung memberikan materi kepada siswa. Sebaiknya siswa diberikan kesempatan untuk membangun pengetahuannya sendiri. Pengajaran dianggap setara dan identik dengan pembelajaran dengan siswa yang aktif (Suyono, 2011). Pembelajaran dipandang sebagai suatu sistem yang terdiri dari komponen-komponen yang saling berkaitan satu sama lain, serta terorganisir antara kompetensi yang harus diraih siswa, materi pelajaran, pokok bahasan, metode dan pendekatan pembelajaran, media pembelajaran, sumber belajar, pengorganisasian kelas, serta penilaian hasil belajar siswa.

Melalui hasil observasi ang dilakukan oleh peneliti di SDN Blimbing 4 Malang menunjukkan bahwa guru hanya menggunakan baha ajar yang telah dibuat oleh pemerintah ataupun lembaga lain. Bahan ajar pada Kurikulum 2013 yang digunakan yaitu buku guru dan buku siswa. Dalam pelaksanaan penggunaan buku siswa terlihat permasalahan bahwa materi yang terdapat dalam buku siswa kurang melatih pemahaman, kemandirian dan kreativitas siswa dalam materi pecahan. Berdasarakan kondisi tersebut guru diwajibkan untuk mengembangkan bahan ajar tersebut agar dapat meningkatkan pemahaman siswa pada materi pecahan.

Pemberian bahan ajar berupa modul yang dibuat oleh guru juga memiliki manfaat dalam perkembangan prestasi siswa. Modul yang dibuat oleh guru sebaiknya mengarah pada keadaan lingkungan sekitar siswa. Modul adalah sebuah buku yang ditulis dengan tujuan agar peserta didik dapat belajar secara mandiri tanpa atau dengan bimbingan guru, sehingga modul berisi paling tidak tentang segala komponen dasar bahan ajar, yaitu: 1) petunjuk belajar (petunjuk siswa atau guru), 2) kompetensi yang akan dicapai, 3) informasi pendukung, 4) latihan-latihan, 5) petujuk kerja yang dapat berupa Lembar Kerja (LK), dan 6) evaluasi (Majid, 2008).

Selain dengan modul pembelajaran, diperlukan pula alternatif pembelajaran yang berpusat pada siswa dan menyajikan konsep pembelajaran matematika yang berkaitan dengan kehidupan sehari-hari siswa. Salah satu pendekatan pembelajaran matematika yang bermakna oleh siswa adalah dengan menerapkan Contextual Teaching and Learning (CTL). Al-Tabany (2014) menerangkan komponen Contextual Teaching and Learning (CTL) yaitu (1) konstruktivisme, (2) inkuiri, (3) bertanya, (4) masyarakat belajar, (5) pemodelan, (6) refleksi dan (7) penilaian.

Melalui pendekatan CTL yang telah diterapkan oleh Sukinah (2017) telah memiliki dampak positif dalam meningkatkan prestasi belajar siswa. Siswa lebih mudah dalam memahami konsep dan materi yang disampaikan karena produk yang akan diberikan berupa modul yang mengaitkan materi pelajaran dengan kehidupan seharihari siswa. Modul dengan pendekatan Contextual Teaching and Learning (CTL) merupakan salah satu perangkat pembelajaran yang mencakup isi materi, metode, serta evaluasi yang dapat digunakan secara mandiri sesuai dengan kecepatan belajar masing-masing individu secara efektif dan efisien. Modul pebelajaran bilangan dengan pendekatan CTL yang telah dikembangkan oleh Suastika and Wahyuningtyas (2018) dapat meningkatkan aktivitas siswa dalam pembelajaran. Serta penggunaan modul pembelajaran matematika dengan pendekatan CTL sebelumnya telah terbukti dapat meningkatkan pemahaman konsep siswa SD (Hamdunah, Yunita, Zulkardi, \& Muhafzan, 2016). Hal ini menunjukkan bahwa modul dapat digunakan untuk belajar siswa kapan saja, dimana saja, tanpa bergantung pada pengajar karena bahasa pada modul telah disusun disesuaikan dengan keseharian siswa.

Modul pembelajaran matematika sebelumnya telah dikembangkan pada materi penjumlahan dan pengurangan bilangan bulat (Wahyuningtyas, Dyah Tri. Shinta, 2017) serta lingkaran dan bola (Hamdunah et al., 2016), sehingga pada penelitian ini akan dikembangkan modul pembelajaran pecahan sederhana bagi siswa kelas III SD. Tujuan penelitian ini mengembangkan modul pembelajaran matematika pada materi pecahan sederhana dengan pendekatan Contextual Teaching and Learning (CTL) yang valid, praktis dan efektif pada siswa kelas III SD.

\section{METODE}

Metode penelitian pengembangan modul pembelajaran pecahan sederhana siswa kelas III SD dengan pendekatan CTL adalah penelitian pengembangan. Model penelitian ini menggunakan model penelitian pengembangan 4-D yang dikembangkan oleh Wahyuningsih, Raharjo, and Masithoh (2013) yang terdiri atas empat tahap, yaitu pendefinisian (define), perancangan (design), pengembangan (develop), dan penyebaran (disseminate). Pada tahap pendefinisian (define), dilakukan identifikasi dan kajian tentang modul pembelajaran yang digunakan di SDN Blimbing 4 Malang khususnya pada pembelajaran matematika kelas 3 tentang materi pecahan sederhana. Pada tahap perancangan (design), dilakukan persiapan dalam pembuatan draft modul yang diawali dengan penyusunan kisi-kisi modul pembelajaran. Kisi-kisi ini digunakan sebagai acuan untuk menyusun modul pembelajaran melalui pendekatan Contextual Teaching and Learning (CTL).

Pada tahap ketiga, yaitu tahap pengembangan (develop). Tahap ini bertujuan untuk untuk menghasilkan 
modul pembelajaran yang sudah direvisi berdasarkan masukan dari para ahli. Dan tahap terakhir yaitu tahap penyebaran (disseminate), pada tahap ini dilakukan pengemasan modul pembelajaran melalui pendekatan Contextual Teaching and Learning (CTL) yang siap untuk disebarkan.

Bentuk instrumen yang akan digunakan dalam penelitian ini adalah sebagai berikut: (1) lembar validasi, (2) lembar observasi, (3) angket respon siswa, (4) tes hasil belajar, dan (5) studi kepustakaan. Teknik analisis data yang digunakan dalam penelitian pengembangan ini menggunakan teknik analisis deskriptif kualitatif dan analisis data kuantitatif. Analisis deskriptif kualitatif digunakan untuk mengelola hasil wawancara dan komentar yang diberikan oleh validator. Sedangkan analisis data kuantitatif diperoleh melalui pengisian angket oleh validator dan responden yang berisikan pertanyaan-pertanyaan yang berhubungan dengan modul pembelajaran yang dihasilkan.

\section{HASIL DAN PEMBAHASAN}

Produk yang dihasilkan pada penelitian pengembangan ini adalah modul matematika melalui pendekatan Contextual Teaching and Learning (CTL) materi pecahan sederhana kelas III SD. Sintaks pendekatan CTL pada modul pembelajaran pecahan sederhana kelas III SD:

Tabel 1.1 Sintaks Modul Pembelajaran Pecahan Sederhana dengan Pendekatan CTL

\begin{tabular}{|c|c|c|}
\hline No & $\begin{array}{l}\text { Komponen } \\
\text { CTL }\end{array}$ & Rencana Modul \\
\hline 1. & $\begin{array}{l}\text { Kontruktivis } \\
\text { me }\end{array}$ & $\begin{array}{l}\text { Ayo Mengamati! } \\
\text { Amatilah warna bendera Indonesia di } \\
\text { lapangan upacara sekolahmu! Melalui } \\
\text { bendera tersebut kamu dapat belajar } \\
\text { pecahan. Coba tebaklah berapa nilai pecahan } \\
\text { dari warna bendera tersebut? }\end{array}$ \\
\hline 2. & Inkuiri & $\begin{array}{l}\text { Ayo Menemukan! } \\
\text { Amatilah gambar potongan pizza berikut! } \\
\text { Bisakah kalian menyebutkan masing-masing } \\
\text { bagian yang didapat oleh setiap orang? }\end{array}$ \\
\hline 3. & Bertanya & $\begin{array}{l}\text { Ayo bertanya! } \\
\text { Buatlah daftar pertanyaan untuk materi } \\
\text { pelajaran yang belum kamu pahami! }\end{array}$ \\
\hline 4. & $\begin{array}{l}\text { Masyarakat } \\
\text { belajar }\end{array}$ & $\begin{array}{l}\text { Ayo bekerjasama! } \\
\text { Buatlah beberapa bentuk pecahan dengan } \\
\text { menggunakan kertas origami. Diskusikan hal } \\
\text { tersebut bersama dengan teman kelompokmu } \\
\text { kemudian presentasikan di depan kelas! }\end{array}$ \\
\hline 5. & Pemodelan & $\begin{array}{l}\text { Ayo ikuti! } \\
\text { Saat temanmu mempresentasikan hasil } \\
\text { diskusi mereka, lipatlah kertas origami } \\
\text { seperti yang dilakukan oleh temanmu } \\
\text { kemudian arsirlah bagian kertas tersebut dan } \\
\text { tentukan berapa nilai pecahan yang } \\
\text { ditunjukkan dari lipatan kertas tersebut! }\end{array}$ \\
\hline 6. & Refleksi & $\begin{array}{l}\text { Ayo renungkan! } \\
\text { Masih ingatkah kamu dengan materi } \\
\text { pelajaran yang telah kalian lakukan? Ayo } \\
\text { baca kembali rangkuman materi di bawah } \\
\text { ini. }\end{array}$ \\
\hline 7. & $\begin{array}{l}\text { Penilaian } \\
\text { autentik }\end{array}$ & $\begin{array}{l}\text { Sekarang aku bisa! } \\
\text { Berilah tanda centang }(\sqrt{ }) \text { jika kamu sudah } \\
\text { bisa, dan tanda silang }(\mathrm{X}) \text { jika kamu belum } \\
\text { bisa pada pernyataan di bawah ini! } \\
\text { Ayo Kerjakan! }\end{array}$ \\
\hline
\end{tabular}

\begin{tabular}{lcc}
\hline No & $\begin{array}{c}\text { Komponen } \\
\text { CTL }\end{array}$ & \multicolumn{1}{c}{ Rencana Modul } \\
\hline & $\begin{array}{l}\text { Untuk } \\
\text { kerjakan }\end{array}$ & mengukur \\
& & somampuanmu, ayo berikut ini dengan benar! \\
\hline
\end{tabular}

Sintaks hasil pengembangan modul sejalan dengan komponen CTL menurut Al-Tabany (2014) yaitu kontruktivisme, inkuiri, bertanya, masyarakat belajar, pemodelan, refleksi dan penilaian autentik. Komponen CTL tersebut dikembangkan dalam kegiatan pembelajaran pada modul, sehingga siswa lebih memahami materi pecahan sederhana. Hasil pengembangan modul pembelajaran pecahan sederhana ini sejalan dengan design pengembangan modul dengan pendekatan CTL yang telah dikembangkan oleh Wahyuningtyas dan Suatika (2016).

Modul pembelajaran pecahan sederhana. Validasi desain dilakukan oleh validator yang terdiri dari 2 validator dan 1 praktisi pembelajaran. Validator diberi lembar validasi untuk memperoleh penilaian, kritik, dan saran terhadap modul dan materi dalam modul pembelajaran matematika. Validasi materi dalam modul pembelajaran matematika diberikan oleh dosen matematika Universitas Kanjuruhan Malang dan validasi modul pembelajaran diberikan oleh guru kelas III SDN Blimbing 4 Malang.

Penilaian modul pembelajaran menunjukkan hasil valid, dengan koefisien validitas modul pembelajaran mencapai 96,73\% dan koefisien validitas materi dalam modul pembelajaran mencapai $76,46 \%$. Dengan demikian, modul pembelajaran dapat dikatakan valid dan layak digunakan untuk siswa sebagai pedoman yang berisi materi pelajaran untuk menunjang keberhasilan pencapaian tujuan pembelajaran. Hal ini sejalan dengan penelitian yang dilakukan oleh Suastika and Wahyuningtyas (2018) yang telah mengembangkan modul pembelajaran bilangan dengan pendekatan Contextual Teaching and Learning (CTL) dengan kriteria valid.

Pada tahap penyebaran (disseminate), modul pembelajaran pecahan dengan kriteria valid akan diujicobakan kepada siswa kelas III SD. Hasil dari penggunaan modul pembelajaran pecahan sederhana yaitu memenuhi kriteria praktis dengan hasil persentase aktivitas guru selama dua pertemuan yang secara berturut-turut mencapai persentase $82 \%$ dan $91,42 \%$ dengan kategori baik. Hal ini menunjukkan bahwa modul pembelajaran yang disesuaikan dengan pendekatan Contextual Teaching and Learning (CTL) telah memenuhi kepraktisan. Hal ini sejalan dengan penelitian yang telah dilakukan oleh Astutik (2010) bahwa penggunaan modul pembelajaran matematika dengan menggunakan pendekatan kontekstual dapat meningkatkan aktivitas guru dalam mengelola pembelajaran.

Modul pembelajaran juga dikatakan efektif berdasarkan hasil persentase aktivitas siswa dalam pembelajaran yang memiliki kategori baik dari pertemuan pertama dan kedua yaitu $85,14 \%$ dan $90,85 \%$, persentase respon positif siswa terhadap modul pembelajaran dan proses pembelajaran yang $>80 \%$ yaitu $95,66 \%$, dan rata-rata nilai yang diperoleh siswa kelas III 
SDN Blimbing 4 Malang mendapat skor $\geq 60$, yaitu memproleh rata-rata nilai 88 . Hal ini menunjukkan bahwa ketuntasan hasil belajar minimal telah tercapai sehingga modul pembelajaran pecahan yang telah dikembangkan efektif. Sejalan dengan Wahyuningtyas and Suastika (2017) bahwa penggunaan modul pembelajaran matematika dengan pendekatan Contextual Teaching and Learning (CTL) dapat meningkatkan pemahaman siswa terhadap materi pembelajaran matematika dari $70 \%$ menjadi $85 \%$.

\section{PENUTUP \\ Simpulan}

Hasil pengembangan modul pembelajaran pecahan sederhana siswa kelas III dengan pendekatan Contextual Teaching and Learning (CTL) telah memenuhi kriteria valid berdasarkan hasil validasi modul $96,73 \%$ dan validasi materi $76,46 \%$. Penggunaan modul dapat meningkatkan aktivitas siswa mencapai $5,71 \%$, sehingga telah memenuhi kriteria praktis. Hasil belajar siswa setelah menggunakan modul memenuhi kriteria efektif mencapai nilai 88 . Sehingga modul pembelajaran pecahan sederhana dengan pendekatan CTL layak digunakan dalam pembelajaran.

\section{Saran}

Bagi guru, modul pembelajaran pecahan sederhana dapat dijadikan bahan pembelajaran matematika. Bagi peneliti lain, diharapkan dapat mengembangkan modul pembelajaran dengan materi matematika yang lain.

\section{DAFTAR PUSTAKA}

Al-Tabany, T. I. B. (2014). Mendesain model pembelajaran inovatif, progresif, dan kontekstual. Jakarta: Prenadamedia Group.

Astutik, D. (2010). Pengembangan Modul Pembelajaran Matematika Materi Balok dan Kubus secara Kontekstual untuk Siswa Kelas V Sekolah Dasar. SKRIPSI Jurusan Matematika-Fakultas MIPA UM.

Hamdunah, H., Yunita, A., Zulkardi, Z., \& Muhafzan, M. (2016). Development A Constructivist Module and Web on Circle and Sphere Material with Wingeom Software. Journal on Mathematics Education, 7(2), 109-116.

Majid, A. (2008). Perencanaan pembelajaran mengembangkan standar kompetensi guru. Bandung: PT. Remaja Rosdakarya.

Suastika, I. K., \& Wahyuningtyas, D. T. (2018). Developing Module of Fractional Numbers using Contextual Teaching and Learning Approach. Pancaran Pendidikan, 7(1).

Sukinah, S. (2017). Penerapan Model Pembelajaran Contextual Teaching And Learning Sebagai Upaya Untuk Meningkatkan Prestasi Matematika Materi Peluang. Jurnal Pendidikan (Teori dan Praktik), 1(2), 190-204.
Sunarto, H., \& Hartono, A. (2008). Perkembangan peserta didik. Jakarta: Rineka Cipta.

Suyono, H. (2011). Belajar dan Pembelajaran. Bandung: Remaja Rosdakarya.

Wahyuningsih, T., Raharjo, T., \& Masithoh, D. F. (2013). Pembuatan Instrumen Tes Diagnostik Fisika SMA Kelas XI. Jurnal Pendidikan Fisika, 1(1), 111-117.

Wahyuningtyas, D. T., \& Suastika, I. K. (2017). Developing of Numbers Learning Module For Primary School Students Bycontextual Teaching and Learning Approach. JPDI (Jurnal Pendidikan Dasar Indonesia), 1(2), 33-36. 